\title{
MORFOTIPOS EM MACHOS DE MACROBRACHIUM BRASILIENSE (CARIDEA: PALAEMONIDAE)
}

\author{
Nogueira, C.S. ${ }^{1,}$; Pantaleão, J.A.F. ${ }^{1}$; Almeida, A.C. ${ }^{2}$ \& Costa, R.C. ${ }^{1}$ \\ ${ }^{1}$ Universidade Estadual Paulista "Júlio de Mesquita Filho" (UNESP), Campus Bauru, \\ Laboratório de Biologia de Camarões Marinhos e de Água Doce. \\ ${ }^{2}$ Universidade Federal de Uberlândia (UFU), Campus Umuarama. \\ Laboratório de Ecologia e Ecossistemas Aquáticos. \\ *Autor correspondente: caiosnogueira@hotmail.com
}

Em algumas espécies de decápodes é possível verificar variações morfológicas em indivíduos adultos de uma mesma população, as quais resultam em distintos morfotipos. Esses morfotipos podem influenciar a estrutura da população, muitas vezes representando um caráter relacionado à dominância social e reprodução. $\mathrm{O}$ crescimento relativo de Macrobrachium brasiliense foi analisado a fim de investigar a ocorrência de distintos grupos morfológicos em machos adultos. Os espécimes analisados foram coletados no córrego Água Limpa, na região do Triângulo Mineiro, Brasil. Os espécimes foram coletados ao longo da margem do córrego com o uso de peneiras. Cada macho foi medido em relação a sete dimensões corporais: comprimento da carapaça (CC), comprimento do maior quelípodo (CMQ), comprimento do dáctilo (CD), comprimento do propódo $(\mathrm{CPr})$, comprimento do carpo (CCr), comprimento do mero (CM) e comprimento do ísquio (Cl). O crescimento relativo foi analisado com base na mudança dos padrões de crescimento das estruturas corpóreas mencionadas (variáveis dependentes) em relação ao CC (variável independente). Em seguida, uma análise exploratória (análise de componentes principais - PCA) foi realizada com os dados morfométricos em busca de possíveis grupos morfológicos distintos na população. Dois morfotipos foram identificados entre os indivíduos adultos: o morfotipo 1, com quelípodos menos desenvolvidos $(22,35 \pm 3,36 \mathrm{~mm})$ e com poucos espinhos ou em formação, e o morfotipo 2, com quelípodos maiores $(36,57 \pm 12,49 \mathrm{~mm})$, muitos espinhos ao longos dos mesmos, principalmente a partir do mero, e todos os espinhos completamente desenvolvidos. Os resultados da relação entre CC vs CMQ diferiu significativamente $(p<0.01)$ entre os dois morfotipos. Foi feita uma miniciosa descrição com base nos principais caracteres macroscópicos de diferenciação entre os morfotipos, para se tornar mais fácil a identificação em pesquisas futuras. As castas podem possuir diferentes funções em uma população, como já descrito em outros trabalhos para outras espécies, inclusive do mesmo gênero. Portanto, recomenda-se que seja realizada a identificação dos morfotipos em futuras pesquisas relacionadas a biologia ou ecologia de $M$. brasiliense, tendo em vista a influência de tal presença na dinâmicadas populações dessa espécie.

Palavras-chave: camarão de água doce, crescimento relativo, dominância. 